\title{
Antropología del territorio ${ }^{1}$
}

\author{
Francisco Ther Ríos \\ Centro de Estudios del Desarrollo Local y Regional, Universidad de Los Lagos. \\ Osorno, Chile. E-mail: fther@ulagos.cl
}

\begin{abstract}
Resumen: Los procesos de internacionalización de capitales, así como también el efecto de los medios de comunicación y la producción del conocimiento con sus estrategias racionalizadoras, generan globalmente movimientos sobre los territorios y, muy particularmente, sobre aquellos territorios ricos en biodiversidad; los cuales son presionados para abrirse y negociar productos, patrimonios, experiencias y significados. Desde un punto de vista sociocultural, la apertura vivida en lo local implica que los territorios pongan en juego diferentes esquemas adaptativos. Adaptaciones que requieren la colaboración y coayuda de las Ciencias Sociales. El objetivo del artículo es explicitar una estrategia metodológica que, en concordancia a un corpus discursivo vinculado a la complejidad, posibilite investigaciones en los territorios locales y con ello se potencie interlocuciones con lo global. En este sentido, la Antropología del Territorio constituye una aproximación teóricometodológica reflexiva y activa, cuyos atractores investigativos son los imaginarios territoriales y los modos de vivir y habitar.

Palabras clave: Imaginarios territoriales, modos de vivir y habitar, complejidad territorial, interdisciplina y sustentabilidad, territorios vividos/territorios normados.
\end{abstract}

\section{Anthropology of territory}

\begin{abstract}
The internationalization of capital, as well as the effect of media and knowledge production with rationalizing strategies, globally generate movements in the territories, and particularly on those areas rich in biodiversity, which are under pressure to open and trading products, assets, experiences and meanings. From a sociocultural perspective, the interest lived at local scale implies that the territories come up with different adaptive schemes. Adaptations that require collaboration and co-help of Social Sciences. The article aims to explain a strategy that, according to a discursive corpus linked to complexity, enables research in local areas and thereby enhance interlocutions with the global. In this sense, anthropology of the Territory is a theoretical-methodological approach reflective and active, whose attractors are the imaginary territorial research and ways to live and dwell.
\end{abstract}

Key words: Territorial imaginary, ways of life and living, territorial complex, interdisciplinary and sustainability, territories lived/regulated territories.

\section{Antropologia do território}

Resumo: A internacionalização do capital, bem como o efeito da mídia e produção de conhecimento com as estratégias de racionalização, geram movimentos nos territórios a nível mundial, e particularmente nas áreas ricas em biodiversidade, que estão sob pressão para abrir a comercialização de produtos, bens, experiências e significados. De uma perspectiva sociocultural, apertura do local nos territórios 
implica pôr em jogo diferentes esquemas adaptativos. Adaptações que exigem colaboração e coayuda de Ciências Sociais. O artigo tem como objetivo explicar uma estratégia que, de acordo com um corpus discursivo ligado à complexidade, permite a pesquisa em áreas locais e, assim, aumentar interlocuções com o global. Neste sentido, a antropologia do Território é uma abordagem teórico-metodológica reflexiva e ativa, cuja atratores são a pesquisa do imaginário territorial eas maneiras de viver e habitar.

Palavras-chave: Imaginário territorial, formas de vida e de viver, complexo territorial, interdisciplinar e sustentabilidade, os territórios viveu / regulado territórios.

\section{Introducción}

El territorio se inscribe y relaciona con los procesos de descentralización, regionalización y democratización; estos procesos suponen la existencia de lógicas u orientaciones subyacentes que las articulan. Una lógica u orientación no siempre se deja ver explícitamente, más bien se resiste a ello. Esquemáticamente, se reconocen a lo menos dos orientaciones teóricas cuando se habla y discute sobre el territorio y su planificación: se trata de la perspectiva teórica neoliberalista y la de los teóricos del desarrollo (y la planificación regional). Según Amtmann (1997), mientras que para la primera, la descentralización se refiere a un modo de organización políticaadministrativa del territorio donde se busca poner fin al centralismo decisorio; para los segundos en cambio, la descentralización se refiere esencialmente a la búsqueda de estrategias tendientes a lograr la transferencia del poder, no sólo administrativamente, sino que por medio de la ampliación de los derechos y libertades. Con leves diferencias, estas orientaciones teóricas están dominadas por las especializaciones sectoriales que carecen de visión de conjunto y resultan ser incapaces de hacer síntesis de los análisis. Ambas también se rigen por formulas reductoras; en la práctica, estas orientaciones se expresan a través de manifestaciones economicistas que reducen y subordinan los territorios a intereses de tipo económico. Las visiones y gestiones simplistas del fenómeno complejo de la descentralización-regionalización-democratización resultan ser una reducción del territorio y de lo sociocultural, acabando por esconder y agravar los problemas que se pretenden intervenir. En definitiva, ambas orientaciones son epifenómenos de la cultura disciplinaria, racionalizadora, fragmentada y parcial que crea y mantiene certidumbres.

Hoy resulta más que nunca urgente reconocer la interretroacción existente entre las tres tendencias-desafíos mencionadas, al tiempo que es prioritario dejar de tratarlas de manera inconexa para proponer una visión de conjunto que otorgue respuesta a la complejidad territorial. Desde este punto de vista, la descentralización, por ejemplo, no quedaría reducida a sólo una redistribución del poder, sino más bien abarcaría todos los procesos cotidianos y experienciales del diario vivir. Con lo cual se intenta trascender tanto el reduccionismo -que no va más allá de las partes- como al 
holismo -que no ve más que el todo-. Sí el cartesianismo tradicionalmente ha partido de los conocimientos y competencias disciplinares, cuestión que ha redundado en una verdadera crisis del desarrollo, nuestra propuesta parte con el reconocimiento (develamiento) esencial de las redes de coordinaciones. Es decir, se trabaja intentando hacer inteligible un conjunto de emergencias a partir de la relación entre discursos, hechos y poderes que tratan sobre los territorios locales y su desarrollo, avanzando hacia una potenciación de ellos en el sistema-mundo. De manera implícita, el análisis de estos procesos exige la aplicación de nuevos enfoques y métodos interdisciplinarios, junto a la existencia de modelizaciones que contengan el doble desafío: primero, estar abiertas a la reflexión, y, segundo, ser posibles de aplicar a la realidad local inmediata.

\section{Figura $\mathrm{N}^{\circ}$ 1: Territorios vividos / Territorios normados ${ }^{2}$}

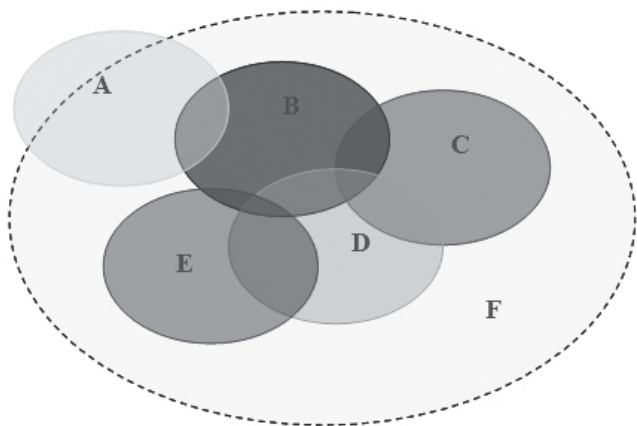

\begin{tabular}{|c|c|}
\hline A, B, C, D, E & 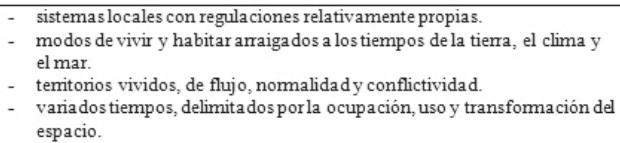 \\
\hline $\begin{array}{l}\text { (A y B) } \\
\text { (B, A, C, D y E) } \\
(\text { C, B y D) } \\
\text { (D, C, B, E) } \\
\text { (E, B y D) }\end{array}$ & $\begin{array}{l}\text { - } \quad \text { sistemas locales compartiendo teritorialidades comunes. } \\
\text { - modos de vivir y habitar en interacción. } \\
\text { - } \text { situaciones de conflictividad. } \\
\text { - sistema de vida compartido basa do en la solidaridad y negociación. }\end{array}$ \\
\hline F & $\begin{array}{l}\text { - existencia de sistema normativo único. } \\
\text { - } \text { territorio normado. } \\
\text { - unúnico tiempo, detemina do por la política que rige y planifica }\end{array}$ \\
\hline
\end{tabular}

(Elaboración propia). Esta es una meta a la cual se ajusta el concepto semiótico de cultura, sistemas en interacción de signos interpretables (Geertz 1996: 27); signos de lo vivido, signos de lo normado.

\section{Territorios vividos}

\section{Territorios normados}

hipertexto de tiempos, memorias, imaginarios, relaciones de poder y conflicto. potencialidades para las diversas colectividades presentes en la región/territorio, y oportunidades para la región posibles de vislumbrar y poner en juego.

Sistema de vida compartido Economía política del "para nosotros" 


\section{Espacio y territorio, el territorio del tiempo espacializado}

Espacio y territorio son conceptos que permanecen relacionados de distinta manera a determinadas disciplinas. Ya sea que hablemos de espacio o de territorio, estos dos conceptos lejos de ser entidades por sí mismas, no le pertenece a ninguna disciplina de manera única y exclusiva. Ninguna disciplina puede reclamarlas como parte de sus dominios conceptuales. Considérese nada más que ambos conceptos han estado trabajados, considerados, tanto desde disciplinas científicas muy deterministas y que suponen sofisticados métodos y técnicas, como es el caso de la Geografía y la Astronomía, como también por disciplinas humanistas y filosóficas. Se escucha hablar del "espacio" en Facultades de Geografía; de igual modo es sobre el "espacio" que se investiga en la NASA. Pero también ya los antiguos griegos hablaban del "espacio filosófico" y los latinoamericanistas desde la literatura y estudios culturales investigan algo que denominan "espacio latinoamericano". También se escucha hablar de "espacio informativo" desde las comunicaciones, de "espacio vectorial” desde las matemáticas, etc.

La mención al territorio como objeto de estudio también es tomada por distintas disciplinas, tanto exactas, como es el caso por ejemplo de la Etología y Ecología, como por Ciencias Sociales, entre estas el territorio resulta ser un concepto regularmente utilizado en Economía o Ecología Política, como también en algunas escuelas teóricas y corrientes antropológicas. También se escucha hablar de "territorio nacional” desde la gobernabilidad de un país, de "territorio indígena" desde la antropología aplicada, etc.

Estos y varios otros conocimientos disciplinares tratan sobre el espacio y/o el territorio. La discusión sobre la relación entre espacio y territorio puede ser interminable y hasta cierto punto también inoficiosa. En ocasiones se ha utilizado a uno como sinónimo del otro, en otras oportunidades para limitar algo distinto, en otras sin hacer mención explícita manejamos sólo a nivel del significado lo que uno de estos conceptos representa en función al otro. En consecuencia, será más bien por la vía de los consensos que logramos hablar con mayor precisión de aquello que investigamos. Llamémoslo espacio, llamémoslo territorio, hace falta una precisión para el consenso. Pero la precisión no sólo nace desde los sistemas de conocimientos, es decir, no son sólo los conocimientos disciplinares los que construyen conceptos y realidades, sino que también estos se construyen a partir de aquello que consensuadamente denominamos como "realidad", a partir de lo cual se determina o reclama, según se estime, la pertinencia de un concepto. Esto significa que la precisión es también pertinencia. Llevado esto último a un acuerdo que nos permita más o menos entender a qué hacemos referencia en nuestras investigaciones de nueva cuenta nos obliga a considerarnos en tanto cientistas sociales como un grupo que discierne, penetra, descifra, aclara y distingue. Pero más que un discurrir discursivo, lo que interesa someter a consideración es la fecundidad que puede llegar a abrir para las Ciencias Sociales una lectura desde la óptica del tiempo de aquello que comúnmente ha sido señalado como espacio. 
Desde la óptica del tiempo, el espacio sirve de contenedor a múltiples actividades. Una Región, una Comuna, un sitio arqueológico, un conjunto de unidades habitacionales, una caverna, son manifestaciones de actividades que se han realizado en el tiempo, y cuya presencia denota esferas de acción y vínculos diversos. El territorio es espacio construido por y en el tiempo. De esta manera, cualquier espacio habitado por el hombre es producto del tiempo de la naturaleza, del tiempo de los humanos, de las distintas formas de organización, y de la concepción cosmogónica del tiempo. Es decir, en lo fundamental, el territorio viene a ser producto del conjunto de relaciones que a diario el hombre entretejió entre todos los suyos con la naturaleza y con los otros.

Esta noción tiene la ventaja de incluir también una dimensión política del territorio. Es decir, en la relación con lo ambiental y con su alteridad el hombre se apropia de espacios, determina rutas, hace señalamientos y escribe en la naturaleza su firma. Influye, afecta y controla acciones mediante el establecimiento de un dominio en un área geográfica específica. Se construye un sentido de la identidad espacial que guarda exclusividad y supone división en la interacción humana. La implicación de todo esto es un modo de comportamiento al interior del contenedor que, en extensión (sincrónicamente, podríamos decir), redundará, necesariamente, en conflicto por el espacio limitado y encuentro con otros distintos quienes también marcan y dejan huellas en la apropiación sociocultural del espacio. El territorio es así más que el espacio; son varios los territorios posibles en un espacio geográfico común. El comportamiento humano genera ritmos interiores que chocan unos con otros. En los territorios fluyen los acontecimientos internos significativos a cada colectividad. Como complemento no menor, el comportamiento humano genera también ritmos particulares. Intensidades. De manera que al hablar de territorio siempre estaremos hablando implícitamente también de dinámicas y conflictos. El pequeño pedazo de terruño conquistado deviene entonces en metamorfosis que implican a quienes viven (o han vivido ahí).

Junto a lo anterior, el territorio también complica a quienes nos dedicamos a investigarlo. Esto no es menor, supone incorporar al estudio del territorio el desarrollo de la Ciencia y del pensamiento, experimentándose una resemantización del espacio como campo relacional, multivariado y complejo, requiriéndose entonces nuevas metodologías para la producción de conocimientos acordes con el estatuto ontológico y metafísico del territorio, asumiéndose al territorio como una unidualidad espacio-temporal de la cotidianeidad siempre relacional, imbricada y conectiva que mantiene implícitamente presente a los entornos ambientales, de alteridad y de producción cultural y económica.

\section{Nociones: los territorios y su investigación}

Los territorios se caracterizan por contar con socio y biodiversidades específicas, al punto que se les identifica por ellas. En la Región de Los 
Lagos en Chile, región-territorio en la cual hemos llevado a cabo básicamente nuestras tareas de investigación, existe una rica y espléndida biodiversidad sobre la cual se evidencian distintos modos de vivir y habitar. La constitución socioantropológica de este sector de Chile reclama de estudios y análisis con aproximaciones teóricas y métodos interdisciplinarios que por sobretodo abarquen las dimensiones identitarias, ecológicas, económicas y políticas, y que, al mismo tiempo, resulten ser propuestas investigativas pertinentes; esto es, el análisis de la construcción territorial en esta zona exige de un tratamiento imaginativo de la diversidad y su expresión territorial. Lo anterior, y dado los tiempos de globalización, se explícita aún más dada la tensión o clivaje existente entre tradición y modernidad, vivenciada en asentamientos humanos del borde costero en el sector sur de la Región, donde se pone en juego un entramado diverso de relaciones territoriales.

Complementando lo anterior, se hace evidente que las territorialidades en el sur de Chile, como en cualquier otro lado, se caracterizarán por el sentido identitario, la exclusividad y la compartimentación de la interacción humana. Es decir, las territorialidades se refieren a comportamientos desplegados en el territorio que se relacionan con la idea de cómo (con qué medios, elementos y motivaciones) se llega a habitar y permanecer en un espacio sobre el cual se impone ritmos de vida y formas de interactuar con lo ambiental y con otros, más o menos distintos, más o menos similares.

De acuerdo con Tizon (1996) el territorio se asocia a las apropiaciones de grupos determinados, lo que en definitiva implica tanto inclusión como exclusión de unos sobre otros. En este sentido, la territorialidad humana estaría en el vértice de un gran número de acciones humanas que implican entre otros, poder, redistribuciones, funcionalidad, dependencia, abrigo y conflicto. Otros autores (Lecoquierre y Steck, 1999, citado por Giménez, G., 2004) trabajando con los conceptos de territorio y territorialidad han señalado que estas nociones remiten a una representación social del espacio que une al interior y separa del exterior a los habitantes de una localidad. Estos autores complementan dicha noción atribuyendo al territorio una construcción colectiva, de grupo y ethos, referida a un "espacio apropiado" por un grupo social para garantizar su sobrevivencia y reproducción. De manera que el estudio del territorio -es decir, el espacio biofísico cargado de actividades humanas, de historia e imaginarios- es materia de interés político, económico y antropo-cultural. En la actualidad a los estudios del territorio se les exige evidenciar sistemáticamente las relaciones entre distintos elementos próximos, pero también entre estos y otros elementos más lejanos. La exigencia incluye representar las distintas disposiciones de tipo contextural que ligan y separan al mismo tiempo distintas escalas y niveles territoriales, así como también explicitar las potencias de los territorios a nivel intralocal, interterritotial, local/global.

En este sentido, la aproximación a los territorios se fundamenta en las concepciones y valoraciones que hacen de ellos sus propios habitantes, 
pero también los territorios son el resultado de la construcción de conocimientos. Para el abordaje y conocimiento de los territorios, podemos decir junto con Claval (2002) que "en cierta manera el espacio se asemeja a un texto, puesto que está cargado de mensajes que, en ocasiones, le confieren un sentido. Quienes lo modelan, intentan plasmar en su realidad sus perspectivas, sus sueños y esperanzas”.

Junto a estos últimos trabajos, lo de mayor importancia para hacer inteligibles las dinámicas y transformaciones territoriales es el concepto de modelización de Le Moigne (1999). La cual considera parte de una epistemología constructivista para especificar una epistemología proyectiva constructivista caracterizada por incorporar fuertemente lo inesperado, procesual e irreversible y otorgar especial relevancia a la acción de un sistema tanto en su dimensión sincrónica como diacrónica. En este sentido, la modelización o representación de las acciones u operaciones (y no de los objetos o cosas) implica también considerar en el centro del análisis al tiempo creador (en el sentido bergsonniano). En nuestro caso, la acción es entendida como acción de distintas racionalidades que actúan sobre el territorio por medio de prácticas concretas. La modelización implicará entonces representar/diseñar intencionalmente símbolos sobre los usos y apropiaciones territoriales, en tanto formas (sintaxis) que a la vez informan (semántica) y transforman (pragmática) los territorios; todo con de fin de comprender con pertinencia la trama de relaciones que construyen las prácticas y saberes en territorios específicos.

\section{Problematizando: el territorio y las Ciencias de la Complejidad}

El conocimiento tiende a una verdad, y para ello construye técnicas y metodologías. Buscándose construir certezas, el conocimiento se constriñe a prácticas y fórmulas políticas para acercarse por repetición y comprobación a un mundo único y conocido cargado de concreciones medibles y situaciones reducidas a formas. El cartesianismo se ha erigido en "doctrina única por la ciencia positiva”, sacralizando el análisis, "o dicho de otra manera, la disociación de ideas, erigiendo así las barreras impenetrables entre las disciplinas” (Le Moigne 2001).

En la cotidianeidad de la ciencia, tanto el lego como el científico, creen como verdaderos e intranzables la información proveniente del quehacer científico ¿Qué pasaría si un estudio científico revela que son falsas algunas de las creencias que hoy sustentamos? Los cientistas sociales estamos presionados a neutralizar la efectividad de nuestros estudios: el sociólogo limita su estudio a temas "seguros" (por ejemplo, la estructura social, aplicando para ello métodos impersonales como encuestas y estadísticas). Por su parte el antropólogo, ha transformado en un credo profesional el estudio de otras culturas (llámense culturas indias, primitivas, pobres, etc.) con el fin de lograr un análisis de nuestra propia cultura. 
Hoy en día, tenemos quizás más que nunca una necesidad de situar, reflexionar y reinterrogar nuestro conocimiento, es decir, "conocer las condiciones, posibilidades y limites de sus aptitudes para alcanzar la verdad a la que tiende” (Morin 1994:18). Como señala Ribeiro (1976), se hace necesario -pero en gran medida también improcedente- ir más allá de las certidumbres, atravesar los miedos y avanzar en la comprensión de los procesos. "El miedo de lo que podamos descubrir nos impele a rechazar un examen cuidadoso de nuestras creencias más profundas, pero tal examen es ineludible si queremos alcanzar a comprender el mundo de nuestros días”.

Adentrarse en el conocimiento que supere las certezas, disyunciones y reducciones deterministas, implica investigar apuntando hacia los sentidos relacionales de "la realidad". Considerando que "la génesis cognitiva muestra que el pensamiento científico es un pensamiento que relaciona, que funciona por metáfora” (Le Moigne 2001) se tendrá como consecuencia la posibilidad de abrir la investigación hacia campos de interpretación y comprensión de los fenómenos y sus fronteras. En el caso de las actividades humanas -todas ellas-, poseen niveles de correspondencia que fractalizan las realidades en unidades de espacio y tiempo con intersticios permeables hacia procesos abiertos, continuos y discretos. En el intersticio -puntos que simultáneamente pertenecen al espacio interior y al espacio exterior, y donde se produce el intercambio de información y energía-, el dinamismo, la imaginación y el juego fluyen para hablar de la vida, de la integralidad, y del devenir de lo homogéneo/heterogéneo. Ubicarnos ahí, en la frontera permeable -movible y penetrable-, nos identifica de nueva cuenta con asociaciones de ideas, creencias y conceptos que dialogan, a fin de constituir miradas nuevas, perspectivas oxigenadas, acerca del territorio.

Curiosamente el avance de la Ciencia nos ha demostrado que ni el holismo ni el relativismo son posibles. Tanto el principio de indeterminación como el principio de incompletud obligan a conocimientos con base recetaria a abrirse hacia la desorganización y reorganización. La no-determinación, que no es simple indeterminación o ignorancia, es creación, surgimiento de otras determinaciones ya existentes o por surgir, emergencias sin que nada las predetermine, salvo las mismas interacciones. Al existir creación y recreación continua reaparece la paradoja del tiempo. En Las leyes del caos Prigogine (1997) comenta las llamadas estructuras disipativas o estructuras de no-equilibrio, las cuales nos permiten comprender todo sistema como una relación de relaciones y no como una simple estructura inmóvil. La relación de relaciones conjugan continuamente tanto la energía que produce y gasta como la interacción con el mundo externo: ambos nos hablan de lo imprevisible. En consecuencia, lo inconcluso toma sentido de realidad procurando colocar con fuerza sobre el tapete las coexistencias de acontecimientos y devenires. Habitamos un "universo donde cada instante es portador de novedad, es decir, de un tiempo y de fenómenos irreversibles. Este universo no es determinista sino 'probabilista', cuando no 'posibilista', y esta condición es 'más cercana, en definitiva, a nuestra condición humana’ ” (Spire, 2000:43). 
De manera que conocer las condiciones, posibilidades y límites del conocimiento implica tender los esfuerzos hacia verdades procesuales. Las Ciencias Sociales abocadas a los estudios territoriales no escapan a esto y se resignifican por medio de enfoques, metodologías e intereses temáticos que en conjunto transgreden lo tradicional y otorgan una esencial preocupación al hombre, sus construcciones y devenires. Se elucida entonces una espiral de conocimientos, saberes y experiencias vinculadas a la producción, negociación y tráfico de significados y significaciones socioculturales posibles de reconocer situándose en espacios geográficos más o menos definidos. $^{3}$

Desde aquella Ciencia de los límites, reconocedora de sus límites tradicionales y al mismo tiempo transgresora de los mismos, se ha avanzado en espiral hacia la emergencia del tiempo en tanto categoría de la transformación y cambio: el tiempo se transforma en la moneda de cambio para el deseo de vida, de lo aún no pensado y del sentido de las existencias. El transcurrir en espiral de las realidades del hombre nos ha llevado, sin necesariamente enunciarlo, a vivir con fuerza en los tiempos contemporáneos.

Estas Ciencias nacen comprometidas con la conectividad creadora. Multiplicidad, vínculos, transformaciones, emergencias, son algunas de la "buenas nuevas" que trae la complejidad. Las múltiples conexiones señalan los múltiples vínculos que sugieren también variadas conexiones. Conectarse es la apertura para el pensamiento. La complejidad apuesta por un acercamiento a lo múltiple, una especie de mapa-vivo otorgado para mentes e identidades que no están cristalizadas todavía y que poseen la voluntad de embarcarse en esa travesía que no soporta mapas con coordenadas fijas (Rajchman, 2004: 10), porque pensar es experimentar. Desde las Ciencias de la Complejidad, entonces, se piensan/reconocen/construyen territorios del conocimiento que no están del todo determinadas. Verdaderamente se trata de un desafío que se nos brinda para enunciar procesos situados y vinculados territorialmente. Territorialización de vínculos, territorialización de tiempos. “...Relacionar bien, ¿̇no es esto el pensamiento complejo?” (Le Moigne 2001).

\section{Construcción 1: Antropología del Territorio, “capturando” el territorio}

La territorialización significa vínculos de variadas conexiones y, como tal, es proceso, acontecer. El territorio es tiempo. Varios tiempos depositados. Entremezclados. Vividos. Coordinación de relaciones. La trasgresión de los límites del conocimiento y los tiempos vividos confluyen en una Ciencia dedicada al territorio. Se trata de una Antropología del territorio, la cual devela al espacio -en tanto soporte biofísico de las actividades humanas-, no como una entidad perteneciente al orden de la yuxtaposición, sino más bien como una forma-proceso de estratos imbricados. Esto es, la Antropología del Territorio resemantiza el espacio, proyectándolo a 
dimensiones temporales entretejidas. Con esta antropología, el territorio no sólo tiene sentido, sino que también adquiere significados y significa. La Antropología del Territorio se presenta en consecuencia como un pensamiento situado y abierto. Pensamiento situado para conocer la profundidad del tiempo de las memorias territoriales; pensamiento abierto a los imaginarios del tiempo de las transformaciones del territorio.

En un sentido operatorio, la investigación del territorio es una “captura”, en tanto aprehensión (lat. apprehensio), desplegada desde los territorios del saber y conocer para aplicarse sobre los territorios de las experiencias situadas con intensidad y extensión. La Antropología del Territorio implica entonces reconocer el entrecruzamiento del tiempo con el espacio a partir de memorias e imaginarios territoriales; desde aquí se abren posibilidades investigativas para tratar abiertamente el juego simultáneo de distintas formas y modos de vivir y habitar, posibles estas mismas de convertirse en atractores investigativos. Decidir qué tipo de relaciones queremos establecer con el territorio estudiado, cómo y qué tipo de registros son posibles de realizar, y para qué se realizan estos, serían algunas de las cuestiones básicas a resolver durante la aprehensión territorial.

Figura $N^{\circ}$ 2: Capturando el territorio (Elaboración propia)

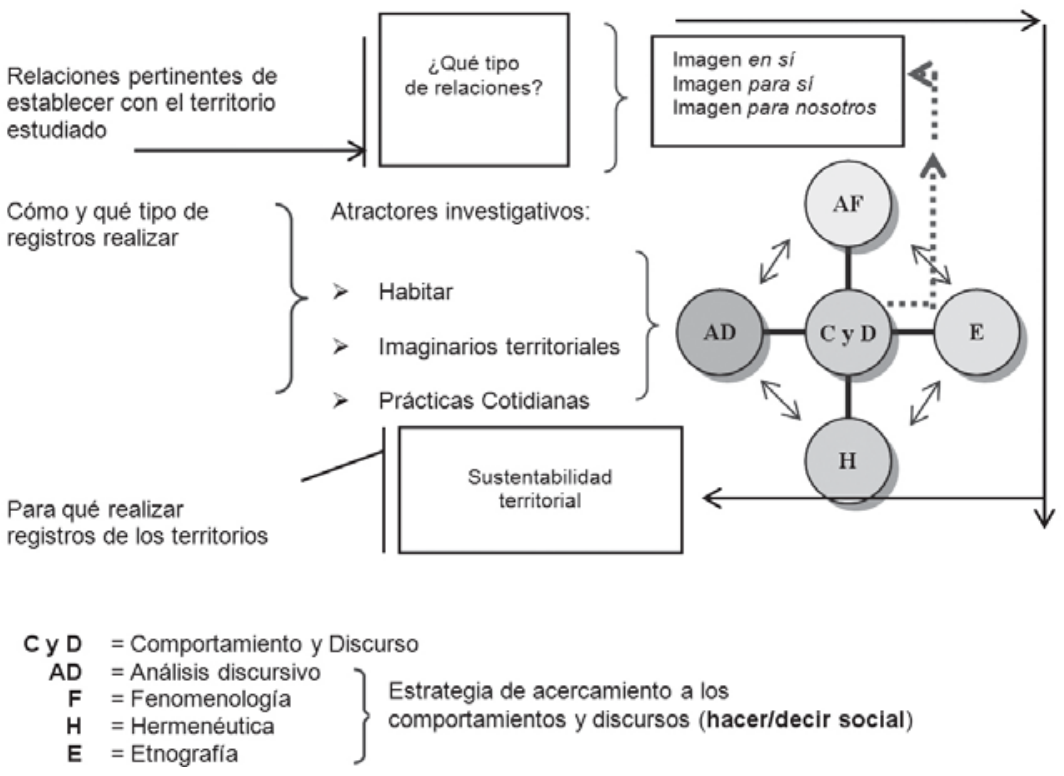


Esta representación de acciones intenta modelizar la “captura” de las experiencias situadas en el territorio. Es innegable la cercanía de este procedimiento con la etnometodología (Coulon 1998) y el interaccionismo simbólico (Blumer 1982). En todos estos procedimientos los discursos también son prácticas, y como tales requieren de la observación directa (incluso con rasgos participativos) así como también del estudio de la oralidad. La diferencia de la Ciencia enunciada, y el tipo de captura del territorio que ella potencia, radica en que esta no abandona la dimensión ética del pensar y abre los territorios hacia su sustentabilidad. La sustentabilidad del territorio, en este caso, remite a una forma no lineal del tiempo para finalmente volver a reconocer a los habitantes de un lugar insertos en un entramado que acontece. Como tal, la captura del territorio viene a constituir una réplica-en proceso del territorio, abierta y en transformación. A partir de ciertos esquemas generativos que permiten a los habitantes de un lugar percibir, ordenar y actuar en el mundo, se logra ir capturando parte de las territorialidades y reconstruir los territorios. Estos esquemas generativos se conforman a lo largo de la historia, suponiendo la interiorización de normas, pautas y formas de proceder en el tiempo y en el espacio; a partir de ellos, se producen los pensamientos, percepciones y acciones en el mundo. Investigativamente, los esquemas generativos territorializados son posibles de captar/deconstruir mediante una estrategia que organiza/construye una "caja de herramientas” con variadas entradas heurísticas, que nos permite, de manera más o menos concreta, aprehender/conocer/capturar tanto las formas en que se organizan distintos modos de vivir y habitar en el territorio, ${ }^{4}$ como los imaginarios territoriales. Ambos atractores investigativos vienen a plasmar analíticamente el hacer/decir social. ${ }^{5}$ De manera que la conducta humana, o lo mismo la cultura, es vista como acción simbólica, a la que se le pregunta por su sentido y valor de manera rigurosa (Geertz 1996); ya que es en el fluir del comportamiento y el discurso donde estos esquemas encuentran su articulación para construir formas culturales territorializables. En este sentido, con el habitar, más allá que proferir la defensa y control sobre el ambiente y los territorios uno de los mayores intentos que pretende realizar la Antropología del Territorio es avanzar en función de la construcción de categorías de fuerte identificación de los grupos con su habitar. Por su parte, con los imaginarios territoriales, en tanto matrices ideoafectivas (Carretero Pasín 2004), se pretende reproducir la creatividad de los grupos y su forma de percibir el mundo para actuar en él, en ocasiones para transformarlo, en otras para preservarlo. De manera que el hacer/decir social se aprehende por medio de la observación, el registro y la interpretación de los comportamientos desplegados sobre los espacios y las experiencias acumuladas a través del tiempo, posibles también de registrar, analizar e interpretar mediante lo dicho (discurso). En definitiva, la Antropología del Territorio sitúa a los sujetos por medio de sus habitares e imaginarios territoriales para desde ahí develar posibilidades de sustentabilidad de sus territorios, es decir, con una Antropología del Territorio se amplía “el universo del discurso humano” (Geertz 1996: 27), y se coayuda para que el sujeto territorial se abra al mundo desde sus propios sentidos existenciales. 


\title{
Construcción 2: territorios vividos / territorios normados en la Región-territorio
}

\author{
Lo anormal, lógicamente secundario, es existencialmente primario \\ Canguilhem
}

La imagen de los territorios construida a través de la Antropología del Territorio deviene en hipertexto de tiempos, memorias, imaginarios territoriales, relaciones de poder y conflicto. Esta intensidad acumulada remite así a memorias, tradiciones, usos y costumbres, pero también remite e incluye a lo nuevo, a lo emergente. Por otro lado, los territorios evidenciados por medio de la Antropología del Territorio se expresan también en extensión, abarcando espacialidades comunes, de tal suerte que se hacen inteligibles encuentros / desencuentros en territorialidades comunes con usos y costumbres variadas. Todo esto queda expresado por ejemplo en la Isla de Chiloé, territorio litoral en el cual no es posible signar taxativamente a los campesinos con delimitadas actividades. En Chiloé, específicamente en el sector de Cucao, los campesinos se dedican tanto a actividades en el borde mar como en el bosque y el campo; conocedores de las bondades de la tierra y el mar organizan sus quehaceres en función a un verdadero reloj de la tierra y el clima. Como caleta de mar abierto, orientada hacia el Océano Pacífico, Cucao exhibe un escaso desarrollo de la tecnología extractiva junto a una fuerte presencia de comunidades Huilliche. Se trata de un asentamiento de 90 viviendas (INE, 2005) y 229 habitantes (111 hombres y 118 mujeres) (Censo, 2002). En cuanto a la economía local las actividades predominantes son la pesca, extracción de leña, pequeña agricultura y el turismo en verano. De la pesca se extrae machas (Mesodesma donacium), cochayuyo (Durvillaea antartica), lapa (Fissurella spp.), piure (Pyura chilensis), róbalo (Eleginops maclovinus) y corvina (Cilus giberti). En Cucao se evidencian entramados territoriales importantes: los tiempos de las memorias y tradiciones potencian distintos vínculos con lo ambiental.

Una segunda expresión de los territorios posibles de cartografiar en la región/territorio denominada como Región de Los Lagos, corresponde a la relación que mantienen las familias de pescadores artesanales con el mar en los distintos asentamientos de pescadores que se ubican en esta región-territorio. En la Caleta Pichicolo, Comuna de Hualaihué, las familias de pescadores artesanales habitualmente se dedican a muchas de las actividades también realizadas por los campesinos chilotes. Por varias décadas han existido continuas migraciones desde Chiloé hacia otros puntos del país y el extranjero; Pichicolo ha sido una de las tantas caletas que han recibido migraciones familiares desde Chiloé. De manera que parte de los usos y costumbres chilotas también han migrado hacia este sector, resemantizándose en parte algunas y cambiando también en parte otras. La caleta Puntilla Pichicolo se encuentra ubicada en el Estero Pichicolo en el sector norte de la comuna de Hualaihué, en el mar interior de Chiloé, se trata de pequeña caleta de pescadores con sólo 158 habitantes (Censo 2002). En cuanto a la economía local, la población se dedica principalmente a las labores asociadas con el mar, la mayoría desarrolla actividades tales como pesca demersal, recolección de mariscos, buceo, acuicultura y 
salmonicultura, siendo la pesca demersal la actividad más rentable por medio de la extracción de la merluza del sur (Merluccius australis) que se extrae durante todo el año, exceptuando el mes de agosto por veda biológica. La mitilicultura con líneas de captación de Choritos (Mythilus chilensis) es una actividad altamente rentable. Un factor positivo son las condiciones geográficas favorables para la captación de semillas de mitílidos. Los tiempos en Pichicolo son los tiempos que sus habitantes van poniendo en uso y práctica, aprendidos hasta cierto punto en el archipiélago de Chiloé y asimismo resignificados e innovados en el nuevo sector y los reclamos y oportunidades que el ambiente y la vida cotidiana otorgan. Simultáneamente, los territorios vividos aquí se encuentran con el tiempo único de las normativas. Si hasta 15 años atrás las familias de pescadores se dedicaban principalmente a la pesca de merluza, ahora las disposiciones legales y el sistema de cuota de captura los empujan a modificar la tradicional relación que han mantenido con el mar. Ya no puede seguir siendo el mar una fuente inagotable de recursos: surgen posibilidades de cultivar el mar y con ello varios trastoques a nivel práctico, social y cognitivo, junto a algunas emergentes estrategias de acomodo. La nueva imagen del territorio por tanto resulta ser una intersección entre los territorios vividos y normados, vislumbrándose una conflictividad entre los tiempos de la cotidianeidad y el tiempo único de la normatividad; su aparente resolución viene igualmente a ser expresión de lo que son los territorios. Desde la óptica de la norma, la cotidianeidad de los territorios vividos se transforma en anormalidad necesaria de corregir.

Complementando lo anterior, en la Región de Los Lagos existe una tercera expresión de territorialidad donde se ponen en juego distintas posibilidades. Lo que acontece en las relaciones cotidianas actuales entre grupos de distinto origen cultural y con presencia histórica en esta parte de Chile, se han plasmado en el presente en una normativa de planificación que postula arbitrariamente una vocación pluricultural para esta regiónterritorio. ${ }^{6}$ Entre los grupos presentes destacan las comunidades mapuche, antiguos habitantes de gran parte de la zona centro sur de nuestro país, y que territorialmente son conocidos en la Región de los Lagos como huilliche.

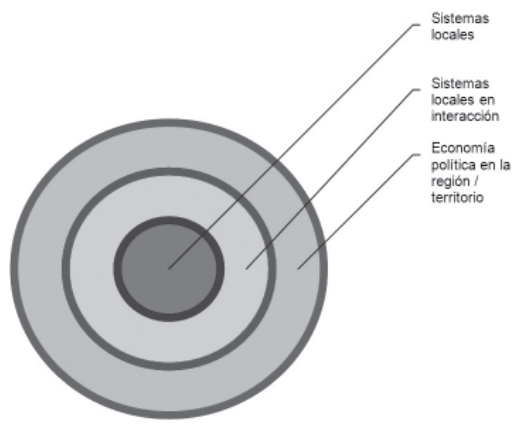

Figura No 3: CONTRACCIÓN/EXPANSIÓN DEL TERRITORIO

$\Rightarrow \quad$ En cada uno de los niveles, al momento de contraerse el territorio éste ๘ 
Íntimamente, en lo más cercano a su morada, los huilliche han ido construyendo varias territorialidades en concordancia con las particularidades ambientales del Futahuillimapu (gran territorio huilliche), las potencialidades de estas geografías, las tradiciones y las regulaciones poliformes y verticales que por largos años les han aplicado el Estado-Nación y los empresarios. En la actualidad, algunos huilliche se mantienen más cercanos a la interculturalidad, otros incluso reacios a la incorporación, algunos otros más proclives a coordinar fuerzas y estrategias con los huincas (blancos). Contrariamente a lo que se ha señalado tradicionalmente por las Ciencias Sociales, la norma aquí ha sido desplegada a posteriori; parafraseando a Canguilhem, diremos entonces que sólo una vez que el acontecimiento se extiende/sucede, y resulta social y valorativamente insuficiente para un sector, surge la norma (Le Blanc, 2004). De manera que la pluriculturalidad y el tiempo oficial único que promueve la norma van incitado un hipertexto de espesor distinto en el cual se congregan tanto potencialidades para las comunidades huilliche como oportunidades para la región/territorio. Pero también, quiebres y debilidades que amenazan con un no siempre deseado equilibrio desequilibrado. En este sistema de vida se ponen en juego distintas manifestaciones de interacción no exentas de conflicto. Pero también, y como siempre, emergen verdaderas adaptaciones a causa de la misma instauración de nuevas normas. Quedamos en presencia de la configuración de una economía política en esta región-territorio; esto es, la arbitrariedad política, productora de normatividad y con ausencia de vínculos con la vida sociocultural, una vez que afecta a los territorios vividos, se imbrica con ellos y genera nuevas formas de individuación en los territorios. Siendo la normalización un intento de racionalización de la región-territorio, aparece como regulación y disciplinamiento. Puesto esto en una perspectiva diacrónica, viene a señalar al territorio como la confrontación entre principios estructurantes (normas) y la historia de su problematización.

\section{Exoducción: construcciones en las que nos hacemos paulatinamente semejante a la cosa conocida}

Las dos construcciones planteadas (1. Captura del Territorio; 2. Territorios vividos / territorios normados) evidencian al territorio en tanto acontecimiento y transformación. Las relaciones que suceden en el territorio, así como los efectos y retroacciones de estas mismas relaciones, construyen los territorios en armonía/desarmonía. Cuanto sucede en el territorio es trazado tanto libre como controladamente. Mientras que lo primero remite a múltiples experiencias de apropiaciones que se dan en el tiempo y cuyo transcurrir orienta variadas formas de vivir y habitar, y cuyas regulaciones se basan principalmente en las costumbres; el control por su parte, básicamente de tipo político, busca producir encuadres convenientes, eliminando la multiplicidad a través de una única mirada.

La cotidianeidad del territorio, en tanto acontecimiento, deviene en territorios vividos, múltiples y locales, muy locales. Cada uno con de los 
territorios con sus propias temporalidades. Son justamente los sistemas locales, situados y al mismo tiempo mucho más amplios que un espacio físico, los que son vividos por los sujetos y actores que lo han construido.

A partir de lo anterior, es importante subrayar que tan significativa como la relación local/global, muy estudiada por economistas y geógrafos, es la relación posible de evidenciar entre territorios locales, y entre éstos y la globalidad. En este sentido, el desarrollo de los territorios es más bien un proceso del tipo local/global/local que acontece desorganizándose y reorganizándose continuamente. Tener como meta el estudio de los territorios considerando esta orientación implica, por tanto, ajustar tanto el corpus discursivo como la estrategia metodológica a un verdadero tratamiento hermenéutico del territorio, cuya operatoria, en última instancia, elucidar interacciones entre sistemas locales de signos de lo "vivido" y "normado" (Ver: Figura N 1). En palabras de Geertz se trata de "sistemas en interacción de signos interpretables (Geertz 1996: 27). La sensibilidad investigativa que construye la Antropología del Territorio, equivale de nueva cuenta -y tal como lo señala Giannini (en Figueroa 2004: 95) a "hacerse paulatinamente semejante a la cosa conocida”, equivale a contar con una “caja de herramientas" pertinentes al objeto de estudio. Sensibilidad y comprensión del objeto de estudio en la que el propio investigador se reconoce recorriendo realidades materiales, culturales y simbólicas. En la relación entre territorios vividos / territorios normados, se denota la complejidad territorial (Ther 2006): los territorios normados remiten inevitablemente a la idea de territorios vividos. Se trata de una normalización entremezclada con la normalidad, y de una cotidianeidad que, entremezclada con el control y la norma, ha interiorizado lo otro. Esto hace que la región-territorio cambie, acontezca. Vida sociocultural y norma política establecen el funcionamiento de la región-territorio por medio de interacciones de tipo solidario y conflictivo entre distintos imaginarios y habitares, al tiempo que permiten esclarecer cuestionamientos sobre las formas de acercarse, aprender y tratar a los territorios. Lo vivido y lo normado, son así el corazón del territorio a estudiar. 


\section{Notas}

${ }^{1}$ Este trabajo es resultado del Proyecto FONDECYT 1080665 «Las sociedades litorales como sistemas de prácticas y saberes tradicionales y científicos: la caleta como modelo de imaginarios pesqueros y dinámicas de uso y apropiación de recursos marinos».

${ }^{2}$ Esta es una meta a la cual se ajusta el concepto semiótico de cultura, sistemas en interacción de signos interpretables (Geertz 1996: 27); signos de lo vivido, signos de lo normado.

${ }^{3}$ Esta espiral de conocimientos, saberes y experiencias se condice con la doble hélice de ADN propuesta por Watson y Crick en 1953 en su artículo "A Structure for Deoxyribose Nucleic Acid” publicado en la revista Nature, vol.171, núm. 4356, pp. 737-738 (25 de abril de 1953). "Desde entonces la doble hélice se ha convertido en el icono de la ciencia moderna: la Mona Lisa de la ciencia moderna” (Kemp 2003, citado por Lacadena).

${ }^{4}$ Las formas de organización de distintos modos de vivir y habitar en el territorio lo señalaremos simplemente como "el habitar".

${ }^{5}$ La hipótesis que subyace a esta estrategia metodológica es que las sociedades contienen en sí mismas sus propias interpretaciones. Lo único que se necesita es aprender la manera de tener acceso a ellas (Geertz 1996: 372). Tanto los imaginarios territoriales como el habitar pueden ser tratados como formas culturales particulares de los esquemas generativos mencionados. Y aunque Levi-Strauss señaló que las formas culturales pueden ser tratadas como un texto de códigos necesarias de descifrar (pues la estructura es la misma, general, universal), la Antropología del Territorio retoma la postura de Geertz en cuanto a que las formas culturales deben ser más bien interpretadas, particularizadas. Al señalar Levi-Strauss la posibilidad de generalizar el estudio cultural explicitó también características universales del hombre: tabú del incesto, producciones mentales similares a toda la especie (mitos); Geertz, por su parte, menciona que aún adoptando una determinada línea teórica, el investigador no puede escribir una teoría general de la interpretación cultural pues el estudio etnográfico es de carácter específico dada la naturaleza de su objeto de estudio (inscripción). De esta manera, la Antropología del Territorio abarca la comprensión/aprehensión del habitar y de los imaginarios, todo en función a cómo se articula el hacer/decir social en situaciones concretas que organizan percepciones, significaciones, emociones, conceptos, actitudes.

${ }^{6}$ La vocación pluricultural queda definida en la Estrategia de Desarrollo Regional de la Región de Los Lagos (2000 - 2010). La norma expresa valores de una parte de la sociedad. Luego, no será posible que surjan las normas, sino es por la decisión de un sujeto que “declara una intención normativa y toma una decisión normadora o normalizante” (Curso no publicado y dictado por Canguilhem en 1942-43 en la Facultad de Letras de Estraburgo. Citado por Le Blanc, 2004: 20). 


\section{Bibliografía}

Amtmann, Carlos (1997), "Identidad regional y articulación de los actores sociales en procesos de desarrollo regional”. Revista Austral de Ciencias Sociales. Volumen No 1, Año 1997.

Blumer, Herbert (1982), El interaccionismo simbólico: perspectiva y método. HORA, Barcelona.

Carretero Pasín, Ángel Enrique (2004), La relevancia sociológica de lo imaginario en la cultura actual. Nómadas Revista Crítica de Ciencias Sociales. Universidad Complutense de Madrid, No 9 (Enero-Junio.2004). Disponible en: http://www.ucm.es/info/nomadas/9/ecarretero.htm

Coulon, A., (1998), La etnometodología. Cátedra, Madrid.

Claval, Paul (2002), "El enfoque cultural y las concepciones geográficas del espacio”. Boletín de la AGE, N 34, 2002, pp 21 - 39.

Figueroa, Maximiliano (2004), “Entrevista a Humberto Giannini. Una Ciudad para el paso humano”. Revista Electrónica Mensual de la Universidad Alberto Hurtado. Sept.- Oct.- Nov. 2004. Disponible en: http://www.boletin. uahurtado.cl/2004/1004/entrevista_giannini.pdf

Geertz, C. (1996), La interpretación de las culturas. Gedisa Editorial, Barcelona.

Giménez, G. (2004), “Territorio, paisaje y apego socio-territorial”. En Primer Foro. Regiones culturales - Culturas regionales. Ciudad de México: CONACULTA, Dirección de Vinculación Regional.

Lacadena, Juan Ramón (2003), En el 50ªniversario del ADN. Disponible en: www.cnice.mecd.es/tematicas/genetica/2003_04/2003_04_04.html

Le Blanc, Guillermo (2004), Canguillem y las normas. Ediciones Nueva Visión, Buenos Aires.

Le Moigne, Jean-Louis (2001), “La asociación de ideas, fundamento del pensamiento complejo”. Artículo publicado en francés por Transversales (Febrero 2001), y en castellano en Iniciativa Socialista (Verano 2001). Disponible en: http://www.inisoc.org/61moigne.htm

Ídem (1999), La modélisation des systemes complexes. Dunod, París.

Morin, Edgar (1994), El Método Tomo III. El conocimiento del conocimiento. Cátedra - Teorema, Madrid.

Prigogine, Ilya (1997), Las leyes del caos. Ed. Crítica, Barcelona. Rajchman, John (2004), Deleuze, un mapa. Ediciones Nueva Visión, Bue- 
nos Aires.

Ribeiro, Darcy (1976), El proceso civilizatorio (de la revolución agrícola a la termonuclear). Editorial Extemporáneos, México D.F..

Secretaría Regional Ministerial de Planificación y Coordinación Región de Los Lagos (2000), Estrategia de Desarrollo Regional 2000 -2010. Gobierno Regional de Los Lagos, Puerto Montt, Chile.

Spire, Arnaud (2000), El Pensamiento de Prigogine. Editorial Andrés Bello, Santiago de Chile.

Ther R., Francisco (2006), “Complejidad territorial y sustentabilidad: notas para una epistemología de los estudios territoriales”. Revista Horizontes Antropológicos, año 12, n. 25: 105 - 115.

Tizon, Philippe (1996), “Qu’ est ce que le territoire?”. En: Les territoires du quotidien, sous la direction de Guy Di Méo (pp. 17-34). L’Harmattan: Paris.

Recibido: 03.05.2011

Aceptado: 21.03.2012 